\title{
Safety and tolerability of duloxetine in the treatment of patients with fibromyalgia: pooled analysis of data from five clinical trials
}

\author{
Ernest H. S. Choy • Philip J. Mease • Daniel K. Kajdasz • Madelaine M. Wohlreich • \\ Paul Crits-Christoph • Daniel J. Walker • Amy S. Chappell
}

Received: 11 August 2008 /Revised: 18 May 2009/Accepted: 19 May 2009/Published online: 18 June 2009

(C) The Author(s) 2009. This article is published with open access at Springerlink.com

\begin{abstract}
The purpose of this report is to describe the overall safety profile of both short- and longer-term duloxetine treatment of fibromyalgia. Data from four double-blind, randomized, placebo-controlled studies (two with 6-month open-label extension phases) and a 1-year, open-label safety study were included. Safety measures included treatment-emergent adverse events (TEAEs), adverse events leading to discontinuation, serious adverse events (SAEs), clinical laboratory tests, vital signs, and electrocardiograms. The most common TEAEs for shortterm treatment with duloxetine were nausea $(29.3 \%)$, headache $(20.0 \%)$, dry mouth $(18.2 \%)$, insomnia $(14.5 \%)$, fatigue $(13.5 \%)$, constipation (14.5\%), diarrhea (11.6\%), and dizziness $(11.0 \%$; all $p<0.05$ vs. placebo). Most
\end{abstract}

\footnotetext{
E. H. S. Choy $(\bowtie)$

Department of Rheumatology, Weston Education Centre,

King's College London,

Cutcombe Road,

London SE5 9RJ, UK

e-mail: ernest.choy@kcl.ac.uk

P. J. Mease

Swedish Medical Center and University

of Washington School of Medicine,

Seattle, WA, USA

D. K. Kajdasz

PGxHealth LLC,

New Haven, CT, USA

M. M. Wohlreich · D. J. Walker · A. S. Chappell

Lilly Research Laboratories,

Indianapolis, IN, USA

P. Crits-Christoph

Department of Psychiatry, University of Pennsylvania,

Philadelphia, PA, USA
}

TEAEs emerged early and were mild to moderate in severity. The profile of adverse events in patients enrolled at least 6 months, and for patients in the 1-year study, was similar to that found in the short-term treatment studies, with no new adverse events emerging at a notable rate. About $20 \%$ of patients discontinued due to adverse events in the short-term treatment studies and in the 1-year study. SAEs were uncommon, and none occurred at a significantly higher frequency for duloxetine compared with placebo. Mean changes in vital signs and weight were small. Rates of treatment-emergent potentially clinically significant (PCS) vital sign, laboratory, and electrocardiogram measures were low, with only PCS rates of alanine aminotransferase being significantly higher for duloxetine compared with placebo in the placebo-controlled treatment studies. In the 1-year study, four patients $(1.1 \%)$ had suicide-related behavior. The data provided here summarize short- and long-term safety from five clinical studies in patients treated with duloxetine for fibromyalgia. In addition, postmarketing surveillance continues for adverse events reported with duloxetine in fibromyalgia, as in other indications.

Keywords Adverse events · Duloxetine · Fibromyalgia . Safety

\section{Introduction}

Fibromyalgia (FM) is a chronic musculoskeletal disorder characterized by widespread pain. The overall prevalence of $\mathrm{FM}$ is about $2 \%$, although rates are higher for women compared with men $[1,2]$. FM is associated with substantial functional disability, work impairments, fatigue, sleep disturbances, and high rates of health care utilization [3-6]. 
To diagnose primary FM, pain must be evident in all four quadrants along with axial skeletal pain for at least 3 months and tenderness must be elicited on physical exam at 11 or more of 18 specified tender point sites [7]. The pain and tenderness in FM is thought by some to be due to central sensitization [8]. Consistent with this hypothesis, patients with FM have qualitatively altered nociception compared with pain-free patients [9-11]. Both serotonin and norepinephrine are believed to play a role in the modulation of pain via the descending inhibitory pain pathways in the brain and spinal cord $[12,13]$. Dysfunction in pain perception is one of the proposed etiological factors in FM, although the exact pathophysiological mechanism of FM is unknown [14-17].

Duloxetine has shown efficacy in placebo-controlled trials in both psychiatric and pain disorders, including major depressive disorder (MDD), generalized anxiety disorder (GAD), diabetic peripheral neuropathic pain (DPNP), and FM [18-32]. The safety of duloxetine has been reported in individual trials and some pooled study analyses [33-36] in patients with MDD, GAD, DPNP, FM, and lower urinary tract disorders. While the safety and tolerability of duloxetine for the treatment of FM have been previously published for the individual clinical trials [1822], a pooled analysis may offer a better overview of this topic than what individual study results can provide. Patients with fibromyalgia are often perceived as having poor tolerance for medications, perhaps related to overall heightened central sensitivity. The purpose of the current article is to present a comprehensive profile of the safety and tolerability of duloxetine during both short- (up to 6 months) and long-term (up to 60 weeks) use in patients with fibromyalgia.

\section{Materials and methods}

\section{Study design}

To evaluate the safety of duloxetine in the treatment of FM, data were drawn from five studies. Studies 1 to 4 were double-blind, randomized, placebo-controlled, multicenter efficacy studies. Study 5 was a 1-year open-label safety study without a placebo control.

In study 1 , patients were randomly assigned to fixed dosages of duloxetine $60 \mathrm{mg}$ BID (twice per day; $n=104$ ) or placebo $(n=103)$. In study 2 , patients were randomly assigned to fixed dosages of duloxetine $60 \mathrm{mg}$ QD (once daily; $n=118)$, duloxetine $60 \mathrm{mg}$ BID $(n=116)$, or placebo $(n=120)$. In study 3 , patients were randomly assigned to fixed dosages of duloxetine $20 \mathrm{mg}$ QD $(n=79)$, duloxetine $60 \mathrm{mg}$ QD $(n=150)$, duloxetine $120 \mathrm{mg}$ QD $(n=147)$, or placebo $(n=144)$. After 15 weeks, patients in the $20 \mathrm{mg}$ duloxetine group were increased to $60 \mathrm{mg} \mathrm{QD}$ and continued on that dose for 13 more weeks. Patients receiving $60 \mathrm{mg}$ duloxetine, $120 \mathrm{mg}$ duloxetine, or placebo during the first 15 weeks were also continued on their respective treatments for 13 more weeks, for a total of 28 weeks of placebo-controlled treatment. Patients who completed the 28-week course of treatment in study 3 were eligible to participate in a further 28-week extension phase in which all patients received $120 \mathrm{mg}$ QD of duloxetine. In study 4 , patients were randomly assigned to 23 weeks of duloxetine treatment ( 8 weeks at $60 \mathrm{mg}$ QD followed by 15 weeks of duloxetine continuing at $60 \mathrm{mg}$ QD or increasing to $120 \mathrm{mg}$ QD depending on clinical response and tolerability; $n=162)$ or placebo $(n=168)$. All patients who completed the initial therapy phase in study 4 were eligible to enter a 29-week double-blind extension phase at either 60 or $120 \mathrm{mg}$ QD depending on dose at the end of the short-term therapy phase. Study 5 had an open-label phase of 8 weeks of duloxetine $60 \mathrm{mg}$ QD treatment $(n=350)$, followed by a 52-week double-blind phase in which patients were randomly assigned in a $1: 2$ ratio to continue at $60 \mathrm{mg}$ QD $(n=104)$ or $120 \mathrm{mg}$ QD $(n=203)$ of duloxetine, respectively. In all studies, patients assigned to doses at or above $60 \mathrm{mg} /$ day were titrated briefly using doses of 20 or $30 \mathrm{mg} /$ day. At study completion or discontinuation, a blinded taper phase lasting 1 or 2 weeks was implemented in all studies to prevent abrupt discontinuation of duloxetine treatment.

All patients provided written informed consent, and all study protocols were approved by the ethical review board at each investigative site. Further details about the methods and procedure of studies 1 through 5 can be found in published reports [18-22].

\section{Patients}

Patients were $\geq 18$ years of age, male or female outpatients (only female for study 2), with or without MDD. All patients met the criteria for FM as defined by the American College of Rheumatology. Patients in all studies were also required to have a score of $\geq 4$ on either the pain intensity item of the Fibromyalgia Impact Questionnaire [37] (study 1) or the average pain item of the Brief Pain Inventory [38] (studies 2-5). Patients were excluded from each study if they had any current primary psychiatric diagnosis other than MDD, including a current or past year diagnosis of dysthymia; had a previous diagnosis of psychosis, bipolar disorder, or schizoaffective disorder; had any anxiety disorder as a primary diagnosis within the past year; had a history of substance abuse or dependence within the past year (excluding nicotine and caffeine); or had a positive urine drug screen for any substances of abuse. Patients with an abnormal C-reactive protein level that is indicative of an 
autoimmune disease, an antinuclear antibody with a dilution of $>1: 320$, or a rheumatoid factor of $\geq 15 \mathrm{IU} / \mathrm{mL}$ were excluded. Patients who were pregnant or breastfeeding, were a serious suicidal risk, or had a serious medical illness were also excluded. At baseline and over the course of the studies, concomitant medications with primarily central nervous system activity were not permitted.

\section{Safety measures}

All studies evaluated safety on the basis of discontinuation rates, treatment-emergent adverse events (TEAEs); serious adverse events (SAEs); laboratory test results, including blood chemistry and hematology; vital signs; weight; and electrocardiograms (ECGs). TEAEs were assessed at each visit by recording patient responses to a general question such as, "How have you been feeling?" TEAEs were coded to Medical Dictionary for Regulatory Activities preferred terms by blinded clinical personnel. An adverse event was considered treatment emergent if it was either new or existing but worsened after initiation of study medication. The severity of each adverse event as mild, moderate, or severe was also recorded. Discontinuation-emergent adverse events were assessed during the 1-2-week tapered discontinuation phases. Suicide-related events were identified by a text string search of adverse events and investigator comments to allow for evaluation of incidences of suicidal ideation or suicidal behavior.

Vital signs consisting of supine and standing blood pressure (BP) and pulse were recorded at each visit. Laboratory tests were performed at regular visits through the treatment periods; ECGs were conducted at the final visit of the short-term phase for study 1 , weeks 15 and 28 for study 3, and weeks 13 and 27 for study 4 (ECGs not conducted postbaseline in studies 2 and 5). The criteria for potentially clinically significant (PCS) ECG values were as follows: PR interval: low - any value $<20$, high - any value $>200$; QRS interval: low - any value $<50$, high — any value $>120$; QTcF interval: abnormal-increase $\geq 30$ from baseline and postbaseline value $\geq 450 \mathrm{~ms}$ for males, $\geq 470 \mathrm{~ms}$ for females. PCS values for vital signs and weight are given in the legend of Table 6 .

\section{Statistical analyses}

To assess duloxetine safety during short-term treatment, data from the 3-and 6-month placebo-controlled phases of studies 1 to 4 were pooled. Longer-term safety and tolerability of duloxetine was examined in two ways: (1) all patients that enrolled in the 60-week study (study 5) and (2) all patients continuing into the 6-month extension phases of studies 3 and 4 and all patients from study 5 maintaining enrollment for at least 6 months (to assess safety in patients with a minimum of 6 months of drug exposure). All analyses were intent-to-treat analyses, unless otherwise specified, using all participants by the groups to which they were assigned by random allocation. Statistical significance was indicated when $p \leq 0.05$. No adjustments were made for multiplicity.

For the placebo-controlled data, comparisons of duloxetine and placebo on rates of TEAEs, reasons for discontinuation, and rates of PCS values for vital signs, weight, laboratory test results, and ECGs were performed using the Cochran-Mantel-Haenszel general association test controlling for study. For vital signs, weight, and ECGs, treatment group differences in mean change from baseline to endpoint (last observation on treatment) were analyzed using an analysis of variance model containing terms for treatment group and study. Time-to-onset and time-to-resolution of adverse events were examined using the product limit approach, and tests for significance between treatment groups were based on the log-rank test. Suicidal ideation and behavior were compared between the duloxetine and placebo groups based on exposure-adjusted Mantel-Haenszel incidence rates derived from the abovementioned text string search.

\section{Results}

\section{Patient characteristics}

The study population of patients $(n=1,411)$ receiving shortterm treatment was primarily $(94.8 \%)$ women. The mean age was $50.2(\mathrm{SD}=11.0)$ years, and most $(87.5 \%)$ of the participants were of Caucasian origin. There were no statistically significant differences between the duloxetineand placebo-treated patients on any of the baseline characteristics (Table 1). Duloxetine-treated patients who had at least 6 months of study participation $(n=721)$ and the sample of 350 patients who participated in the longerterm (1 year) study of duloxetine had similar baseline characteristics, although the minority representation was higher in the 1-year study.

\section{Drug exposure}

For the short-term placebo-controlled studies, a total of 876 patients were exposed to duloxetine for a mean of 110 days, and 535 patients were exposed to placebo for a mean of 105 days. Of the duloxetine-treated patients in these studies, $46.7 \%$ were exposed to drug for at least 3 months (compared with $42.1 \%$ for placebo). For the sample enrolled in studies for at least 6 months, $91.3 \%$ (of 721 patients) were exposed to duloxetine for 6 months or more, and $61.9 \%$ were exposed for 1 year or more with an 
Table 1 Patient characteristics

\begin{tabular}{|c|c|c|c|c|c|}
\hline \multirow[t]{2}{*}{ Variable } & \multicolumn{3}{|l|}{ 3-6-Month studies } & \multirow{2}{*}{$\begin{array}{l}\geq 6 \text {-Month exposure } \\
\text { Duloxetine }(N=721)\end{array}$} & \multirow{2}{*}{$\begin{array}{l}1 \text {-Year study } \\
\text { Duloxetine }(N=350)\end{array}$} \\
\hline & Placebo $(N=535)$ & Duloxetine $(N=876)$ & $p^{\mathrm{a}}$ (duloxetine vs. placebo) & & \\
\hline Ethnicity, $n(\%)$ & & & 0.916 & & \\
\hline African & $13(2.4 \%)$ & $20(2.3 \%)$ & & $5(0.7)$ & $3(0.9)$ \\
\hline Caucasian & $463(86.5 \%)$ & $771(88.0 \%)$ & & $560(77.7)$ & $214(61.1)$ \\
\hline East Asian & $3(0.6 \%)$ & $3(0.3 \%)$ & & $33(4.6)$ & $46(13.1)$ \\
\hline Hispanic & $51(9.5 \%)$ & $76(8.7 \%)$ & & $116(16.1)$ & $82(23.4)$ \\
\hline Nat. Amer. & $1(0.2 \%)$ & $2(0.2 \%)$ & & $4(0.6)$ & $1(0.3)$ \\
\hline Other & $3(0.6 \%)$ & $2(0.2 \%)$ & & - & - \\
\hline West Asian & $1(0.2 \%)$ & $2(0.2 \%)$ & & $3(0.4)$ & $4(1.1)$ \\
\hline Age, years ${ }^{\mathrm{b}}$ & $49.61(11.32)$ & $50.62(10.76)$ & 0.147 & $50.48(10.56)$ & $48.97(11.07)$ \\
\hline Gender, $n(\%)$ & & & 0.265 & & \\
\hline Female & $509(95.1 \%)$ & $829(94.6 \%)$ & & $692(96.0)$ & $335(95.7)$ \\
\hline Height $(\mathrm{cm})^{2}$ & $163.14(7.49)$ & $163.32(7.78)$ & 0.512 & $161.76(7.47)$ & $159.44(7.09)$ \\
\hline Weight $(\mathrm{kg})^{2}$ & $78.15(18.40)$ & $79.71(19.46)$ & 0.582 & $76.84(18.37)$ & $69.95(14.74)$ \\
\hline
\end{tabular}

${ }^{a}$ Frequencies were analyzed using Cochran-Mantel-Haenszel test for general association controlling for study; means were analyzed using a type III sums of squares analysis of variance: model = treatment and study

${ }^{\mathrm{b}}$ Mean (SD)

average exposure period of 327 days. In the longer-term study, 350 patients were exposed to duloxetine for a mean of 298 days, with $69.1 \%$ receiving at least 6 months of exposure and $58.7 \%$ receiving at least 1 year of exposure.

\section{Discontinuations}

Overall, $41.4 \%$ of the duloxetine-treated patients and $42.2 \%$ of the placebo-treated patients discontinued shortterm treatment (Table 2). Adverse events were the cause of early discontinuation for $19.5 \%$ of those in the duloxetine group and $11.8 \%$ in the placebo group during short-term treatment $(p<0.001)$. Lack of efficacy was a reason for discontinuation significantly $(p<0.001)$ less often for duloxetine- compared with placebo-treated patients $(7.0 \%$ and $13.5 \%$, respectively) in the short-term studies. There were no other significant differences in other reasons for discontinuation between the duloxetine and placebo groups in the short-term studies. Among those who were enrolled for at least 6 months, $31.9 \%$ discontinued treatment, with adverse events the most common reason (Table 2). In the 1-year study, $44.9 \%$ discontinued early, with adverse events a reason for discontinuation for $21.1 \%$ of patients (Table 2).

Table 2 Reasons for study discontinuation

\begin{tabular}{|c|c|c|c|c|c|}
\hline \multirow{2}{*}{$\begin{array}{l}\text { Primary reason for } \\
\text { discontinuation }\end{array}$} & \multicolumn{3}{|l|}{ 3-6-Month studies } & \multirow{2}{*}{$\begin{array}{l}\geq 6 \text {-Month exposure } \\
\text { Duloxetine }(N=721) \\
\text { frequency }(\%)\end{array}$} & \multirow{2}{*}{$\begin{array}{l}\text { 1-Year study } \\
\text { Duloxetine }(N=350) \\
\text { frequency }(\%)\end{array}$} \\
\hline & $\begin{array}{l}\text { Placebo }(N=535) \\
\text { frequency }(\%)\end{array}$ & $\begin{array}{l}\text { Duloxetine }(N=876) \\
\text { frequency }(\%)\end{array}$ & $\begin{array}{l}p^{\mathrm{a}} \text { (duloxetine } \\
\text { vs. placebo) }\end{array}$ & & \\
\hline $\mathrm{DC}$ due to any reason & $226(42.2)$ & $363(41.4)$ & 0.44 & $230(31.9)$ & 157 (44.9) \\
\hline Adverse event & $63(11.8)$ & $171(19.5)$ & $<0.001$ & $90(12.5)$ & $74(21.1)$ \\
\hline Lack of efficacy & $72(13.5)$ & $61(7.0)$ & $<0.001$ & $24(3.3)$ & $29(8.3)$ \\
\hline Subject decision & $44(8.2)$ & $59(6.7)$ & 0.16 & $85(11.8)$ & $26(7.4)$ \\
\hline Lost to follow-up & $31(5.8)$ & $38(4.3)$ & 0.06 & $6(0.8)$ & $9(2.6)$ \\
\hline Protocol violation & $14(2.6)$ & $22(2.5)$ & 0.99 & $13(1.8)$ & $9(2.6)$ \\
\hline Physician decision & $2(0.4)$ & $9(1.0)$ & 0.24 & $10(1.4)$ & $8(2.3)$ \\
\hline Sponsor decision & $0(0)$ & $2(0.2)$ & 0.24 & $2(0.3)$ & $2(0.6)$ \\
\hline Entry exclusion criteria & $0(0)$ & $1(0.1)$ & 0.54 & - & - \\
\hline
\end{tabular}

${ }^{\mathrm{a}}$ From Cochran-Mantel-Haenszel test for general association controlling for study

$D C$ discontinuation 


\section{TEAEs}

Most (59.3\%) of the TEAEs reported by duloxetinetreated patients in the short-term studies were described as mild $(21.1 \%)$ or moderate $(38.2 \%)$ in severity. The most common TEAEs as reported by $>10 \%$ of patients during short-term treatment were nausea, headache, dry mouth, insomnia, fatigue, constipation, diarrhea, and dizziness in the duloxetine-treated patients (Table 3). All of these, plus somnolence, hyperhidrosis, and decreased appetite, occurred significantly (all $p<0.05)$ and more frequently in the duloxetine group than the placebo group. No specific adverse events led to discontinuation in the duloxetine group at a significantly higher rate than the placebo group, with the exception of somnolence $(p=0.003$; Table 4).

In the short-term studies, the common $(>10 \%)$ TEAEs occurred early in treatment and had a relatively rapid resolution (Table 3). All of the most common $(>10 \%)$ TEAEs associated with duloxetine had a significantly (all $p<0.05$ ) earlier onset for duloxetine- compared with placebo-treated patients. However, the time from onset to resolution for all of these most common duloxetineassociated TEAEs was not significantly different between duloxetine and placebo.
The same TEAEs that were common $(>10 \%)$ in the shortterm studies were also common among those enrolled for at least 6 months and in the 1-year study (Table 3). In addition, somnolence and hyperhidrosis occurred for more than $10 \%$ of patients. In general, the rates of adverse events among those enrolled for at least 6 months and in the 1-year study were slightly higher than in the short-term studies, but no new adverse events emerged with any frequency. In the 1year study, rates of discontinuations due to specific adverse events were similar to the short-term studies (Table 4).

\section{Serious adverse events}

A total of $21(2.4 \%)$ duloxetine-treated and 11 (2.1\%) placebo-treated patients reported at least one SAE in the short-term studies. There were no statistically significant treatment group differences in the incidence of individual SAEs. Additionally, there was no pattern of SAEs with respect to system-organ class. No one SAE occurred at a frequency greater than others among duloxetine-treated patients. Among the 721 duloxetine-treated patients enrolled for at least 6 months, $42(5.8 \%)$ had an SAE. Similarly, a total of 19 (5.4\%) duloxetine-treated patients experienced at least one SAE in the 1-year study. No specific pattern in the incidence of specific SAEs was

Table 3 Treatment-emergent adverse events

\begin{tabular}{|c|c|c|c|c|c|c|c|c|c|}
\hline \multirow[b]{2}{*}{ Event $^{\mathrm{a}}$} & \multicolumn{7}{|c|}{ 3-6-Month studies } & \multirow{2}{*}{$\begin{array}{l}\geq 6 \text {-Month } \\
\text { exposure } \\
\text { DLX } \\
(N=721) \\
\%\end{array}$} & \multirow{2}{*}{$\begin{array}{l}\text { 1-Year } \\
\text { study } \\
\text { DLX } \\
(N=350) \\
\%\end{array}$} \\
\hline & $\begin{array}{l}\mathrm{PBO} \\
(N=535) \\
\%\end{array}$ & $\begin{array}{l}\mathrm{DLX} \\
(N=876) \\
\%\end{array}$ & $\begin{array}{l}p^{\mathrm{b}} \text { (duloxetine } \\
\text { vs. placebo) }\end{array}$ & $\begin{array}{l}\text { Time to } \\
\text { Onset (days) } \\
\text { PBO } \\
\text { Mdn }\end{array}$ & $\begin{array}{l}\text { DLX } \\
\text { Mdn }\end{array}$ & $\begin{array}{l}\text { Time to } \\
\text { Resolution (days) } \\
\text { PBO } \\
\text { Mdn }\end{array}$ & $\begin{array}{l}\text { DLX } \\
\text { Mdn }\end{array}$ & & \\
\hline Nausea & 11.4 & 29.3 & $<0.001$ & 10.5 & 1.0 & 9.0 & 6.0 & 30.2 & 40.6 \\
\hline Headache & 12.0 & 20.0 & $<0.001$ & 14.0 & 9.0 & 9.0 & 8.0 & 26.1 & 29.4 \\
\hline Dry mouth & 5.2 & 18.2 & $<0.001$ & 13.0 & 4.0 & 32.0 & 73.0 & 22.2 & 17.1 \\
\hline Insomnia & 9.2 & 14.5 & 0.003 & 26.0 & 8.0 & 43.0 & 34.0 & 16.4 & 19.7 \\
\hline Fatigue & 7.1 & 13.5 & $<0.001$ & 26.0 & 7.0 & 39.0 & 54.0 & 12.2 & 11.1 \\
\hline Constipation & 3.6 & 14.5 & $<0.001$ & 16.0 & 10.0 & 74.0 & 47.0 & 18.3 & 17.4 \\
\hline Diarrhea & 7.9 & 11.6 & 0.018 & 14.0 & 3.0 & 5.0 & 4.0 & 14.3 & 12.9 \\
\hline Dizziness & 6.7 & 11.0 & 0.011 & 10.5 & 6.0 & 7.5 & 7.5 & 15.5 & 18.9 \\
\hline Somnolence & 2.8 & 9.6 & $<0.001$ & 2.0 & 3.0 & 59.0 & 50.5 & 11.8 & 14.0 \\
\hline Hyperhidrosis & 1.1 & 6.8 & $<0.001$ & 31.5 & 22.0 & 33.0 & 49.0 & 13.7 & 11.4 \\
\hline Decreased appetite & 0.6 & 6.5 & $<0.001$ & 7.0 & 2.0 & 68.0 & 32.0 & 5.7 & 4.6 \\
\hline
\end{tabular}

Estimates of median times for the adverse events are based on the first new occurrence after initiation of treatment for the subsample of patients who experienced each event.

$P B O$ placebo, $D L X$ duloxetine, $M d n$ median

${ }^{a}$ Event list comprises those treatment-emergent adverse events in the 3-6-month studies for which the rate for duloxetine was $\geq 5.0 \%$ and significantly higher than placebo

${ }^{\mathrm{b}}$ Cochran-Mantel-Haenszel test for general association, controlling for study 
Table 4 Discontinuations due to adverse events

\begin{tabular}{|c|c|c|c|c|}
\hline \multirow[b]{2}{*}{ Event $^{\mathrm{a}}$} & \multicolumn{3}{|l|}{ 3-6-Month studies } & \multirow{2}{*}{$\begin{array}{l}\text { 1-Year study } \\
\text { Duloxetine }(N=350 \\
\%\end{array}$} \\
\hline & $\begin{array}{l}\text { Placebo }(N=535) \\
\%\end{array}$ & $\begin{array}{l}\text { Duloxetine }(N=876) \\
\%\end{array}$ & $p^{\mathrm{b}}$ (duloxetine vs. placebo) & \\
\hline Nausea & 0.7 & 1.9 & 0.074 & 1.4 \\
\hline Insomnia & 0.7 & 1.1 & 0.411 & 2.6 \\
\hline Fatigue & 0.2 & 1.3 & 0.073 & 0.6 \\
\hline Diarrhea & 0.2 & 0.8 & 0.077 & 1.4 \\
\hline Dizziness & 0.6 & 0.7 & 0.672 & 1.4 \\
\hline Somnolence & 0 & 1.5 & 0.003 & 0.3 \\
\hline Vomiting & 0.2 & 0.5 & 0.390 & 2.0 \\
\hline
\end{tabular}

${ }^{a}$ Event list comprises any adverse events that led to discontinuation in $>1 \%$ of patients in either the 3-6-month studies or the long-term study

${ }^{\mathrm{b}}$ Cochran-Mantel-Haenszel test for general association, controlling for study

observed in the 1-year study, and no deaths occurred in any of the five studies.

\section{Suicidality}

Three cases of suicide ideation (one on duloxetine, two on placebo; $p=0.86$ ) were identified during the short-term, placebo-controlled studies. An exposure-adjusted analysis of these rates of suicide ideation also revealed no significant $(p=0.29)$ difference between duloxetine and placebo. In the 1-year study, there were four patients $(1.1 \%)$ who had suicide-related behavior (three suicidal ideations and one suicide attempt).

Vital signs and weight

Mean changes from baseline to endpoint of short-term treatment in the 3-6-month studies for all vital signs were relatively small for duloxetine (Table 5). With the large sample sizes, differences between duloxetine and placebo were statistically significant, with duloxetine evidencing slight increases in pulse, systolic BP, and diastolic BP, and a slight decrease in body weight, relative to placebo. For the sample of patients enrolled for 6 months or more and the 1year study, there were similar small mean changes in vital signs from baseline to endpoint (Table 5).

Rates of treatment-emergent PCS values for vital signs and weight changes were low in the short-term studies (Table 6). No significant differences between the duloxetine and placebo groups were evident for pulse, sitting systolic $\mathrm{BP}$, sitting diastolic BP, body weight, or the incidence of sustained elevation in BP (for systolic BP, $1.3 \%$ in the duloxetine group and $1.1 \%$ in the placebo group had a sustained elevation, $p=0.74$; for diastolic BP, $0.7 \%$ of the duloxetine group and $0.2 \%$ of the placebo group had a sustained elevation, $p=0.17$ ).

Within the sample of duloxetine-treated patients who were enrolled for 6 months or more, treatment-emergent

Table 5 Mean baseline and change (to endpoint) on vital signs and weight

\begin{tabular}{|c|c|c|c|c|c|c|}
\hline & & \multicolumn{3}{|c|}{ 3-6-Month studies } & \multirow{2}{*}{$\begin{array}{l}\geq 6 \text {-Month exposure } \\
\text { Duloxetine } \\
(N=721)\end{array}$} & \multirow{2}{*}{$\begin{array}{l}\text { 1-Year study } \\
\text { Duloxetine } \\
(N=350)\end{array}$} \\
\hline & & $\begin{array}{l}\text { Placebo } \\
(N=527)\end{array}$ & $\begin{array}{l}\text { Duloxetine } \\
(N=855)\end{array}$ & $\begin{array}{l}p^{\mathrm{a}} \text { (duloxetine } \\
\text { vs. placebo) }\end{array}$ & & \\
\hline \multirow[t]{2}{*}{ Pulse } & Baseline & $73.3(9.9)$ & $73.7(9.7)$ & & $74.2(9.5)$ & $75.2(8.7)$ \\
\hline & Change & $-0.4(9.5)$ & $1.2(10.6)$ & 0.003 & $2.3(11.0)$ & $1.9(10.4)$ \\
\hline \multirow[t]{2}{*}{ Sitting diastolic BP } & Baseline & $76.7(9.2)$ & $76.4(8.9)$ & & $77.0(9.2)$ & $76.9(9.3)$ \\
\hline & Change & $-1.2(8.9)$ & $1.0(9.2)$ & $<0.001$ & $0.8(9.5)$ & $-0.2(9.6)$ \\
\hline \multirow[t]{2}{*}{ Sitting systolic BP } & Baseline & $122.5(14.9)$ & $122.3(15.3)$ & & $122.4(15.8)$ & $120.1(14.8)$ \\
\hline & Change & $-1.6(13.2)$ & $0.9(14.7)$ & 0.003 & $0.2(13.9)$ & $-0.1(14,4)$ \\
\hline \multirow[t]{2}{*}{ Weight (kg) } & Baseline & $77.9(18.2)$ & $79.9(19.5)$ & & $76.8(18.4)$ & $69.9(14.7)$ \\
\hline & Change & $0.3(2.4)$ & $-0.4(4.2)$ & 0.002 & $0.6(5.0)$ & $0.7(4.3)$ \\
\hline
\end{tabular}

${ }^{a}$ From analyses of variance with study and treatment as effects

$B P$ blood pressure 
Table 6 Vital signs and weight: treatment-emergent potentially clinically significant values

\begin{tabular}{|c|c|c|c|c|c|c|}
\hline & \multirow[b]{2}{*}{ Abnormality } & \multicolumn{3}{|c|}{ 3-6-Month studies } & \multirow{2}{*}{$\begin{array}{l}\geq 6 \text {-Month exposure } \\
\text { Duloxetine } \\
(N=721) \\
n / N(\%)\end{array}$} & \multirow{2}{*}{$\begin{array}{l}\text { 1-Year study } \\
\text { Duloxetine } \\
(N=350) \\
n / N(\%)\end{array}$} \\
\hline & & $\begin{array}{l}\text { Placebo } \\
(N=535) \\
n / N(\%)\end{array}$ & $\begin{array}{l}\text { Duloxetine } \\
(N=876) \\
n / N(\%)\end{array}$ & $\begin{array}{l}p^{\mathrm{a}} \text { (duloxetine } \\
\text { vs. placebo) }\end{array}$ & & \\
\hline \multirow[t]{2}{*}{ Pulse } & High & $1 / 527(0.2)$ & 4/855 (0.5) & 0.308 & $1 / 721(0.1)$ & 2/347 (0.6) \\
\hline & Low & 2/519 (0.4) & $3 / 846(0.4)$ & 0.900 & $0 / 716(0)$ & $0 / 348(0)$ \\
\hline \multirow[t]{2}{*}{ Sitting diastolic BP } & High & $1 / 522(0.2)$ & 6/847 (0.7) & 0.159 & $1 / 712(0.1)$ & $8 / 342(2.3)$ \\
\hline & Low & $3 / 523(0.6)$ & $3 / 852(0.4)$ & 0.607 & 2/718 (0.3) & 3/346 (0.9) \\
\hline \multirow[t]{2}{*}{ Sitting systolic BP } & High & $1 / 525(0.2)$ & $3 / 848(0.4)$ & 0.415 & 3/715 (0.4) & 6/347 (1.7) \\
\hline & Low & $3 / 517(0.6)$ & $2 / 845(0.2)$ & 0.525 & $1 / 708(0.1)$ & $11 / 340(3.2)$ \\
\hline \multirow[t]{2}{*}{ Weight (kg) } & Gain & 2/499 (0.4) & $10 / 823(1.2)$ & 0.126 & $55 / 719(7.6)$ & $28 / 348(8.0)$ \\
\hline & Loss & 6/499 (1.2) & $18 / 823(2.2)$ & 0.173 & 29/719 (4.0) & $17 / 348(4.9)$ \\
\hline
\end{tabular}

Criteria for PCS values: systolic low ( $\leq 90$ and decrease from baseline $\geq 20$ ), systolic high $(\geq 180$ and increase from baseline $\geq 20)$, diastolic low ( $\leq 50$ and decrease from baseline $\geq 15$ ), diastolic high ( $\geq 105$ and increase from baseline $\geq 15$ ), pulse low ( $\leq 50$ and decrease from baseline $\geq 15$ ), pulse high ( $\geq 120$ and increase from baseline $\geq 15$ ), weight low (decrease from baseline $\geq 10 \%$ ), high (increase from baseline $\geq 10 \%$ )

$N$ number of patients at risk of having potentially clinically significant (PCS) values at baseline, $n$ number of patients with a PCS postbaseline measurement

${ }^{a}$ Cochran-Mantel-Haenszel test for general association, controlling for study

PCS increases in weight were evident for $7.6 \%$ of individuals; $4.0 \%$ had PCS decreases in weight. Rates for treatment-emergent values for vital signs were very low $(0 \%$ to $0.4 \%)$. Similar results were evident in the 1 -year study (Table 6).

A total of $2.2 \%$ (16 of 721 ) of patients enrolled for 6 months or more had a sustained elevation in systolic BP; $2.1 \%$ (15 of 721) had a sustained elevation in diastolic BP. In the 1-year study, sustained elevations in systolic BP occurred for five $(1.4 \%)$ patients and sustained elevations in diastolic BP occurred for $10(2.9 \%)$ patients.

\section{Electrocardiogram}

There were no significant treatment group differences in the incidence of PCS values for any ECG parameters in the 3-6-month pooled study data. PCS rates for duloxetine and placebo were as follows: PR interval (high) - $1.1 \%, 2.3 \%$, $p=0.19$; PR interval (low) $-3.0 \%, 1.4 \%, p=0.09$; QRS (high) $-1.3 \%, 1.2 \%, p=0.68$; QRS interval (low) $-0 \%$, $0 \%$; QTcF (abnormal) $-0.4 \%, 0.3 \%, p=0.79$. Mean changes from baseline to endpoint in ECG intervals for duloxetine and placebo, respectively, were as follows: PR (-3.3 ms, $1.0 \mathrm{~ms}, p<0.001)$, QRS $(-0.3 \mathrm{~ms}, 0.4 \mathrm{~ms}$, $p=0.32)$, QT ( $-5.3 \mathrm{~ms}, 1.7 \mathrm{~ms}, p<0.001)$, QTcB (4.8 ms, $1.9 \mathrm{~ms}, p=0.06)$, and QTcF (1.3 ms, $1.9 \mathrm{~ms}, p=0.26)$.

Chemistry and hematology

Rates of treatment-emergent PCS laboratory values were low in all studies. In the short-term studies, there was a significantly $(p<0.05)$ higher incidence of alanine aminotransferase (ALT) values $>5$ times upper limit of normal (PCS criteria) among duloxetine-treated patients $(0.6 \%)$ compared with placebo-treated patients $(0 \%)$. There were no significant differences between duloxetine and placebo in the rates of treatment-emergent PCS values for aspartate aminotransferase, bilirubin, calcium, cholesterol, creatine phosphokinase, creatinine, gamma-glutamyltransferase (GGT), inorganic phosphorus, sodium, total protein, urea nitrogen, or uric acid (all rates $<1.2 \%$ ). For those patients enrolled for 6 months or more, treatment-emergent PCS values occurred at a rate $>1 \%$ only for high cholesterol $(1.6 \%, 11$ of 706 ; PCS criteria $=$ total cholesterol greater than $7.76 \mathrm{mmol} / \mathrm{L})$. In the 1-year study, two treatmentemergent PCS values occurred at a rate $>1 \%$ : high cholesterol (2.1\%) and high GGT (1.5\%) PCS criteria for GGT $=$ greater than $135,000 \mathrm{U} / \mathrm{L}$ for women and greater than $195,000 \mathrm{U} / \mathrm{L}$ for men).

There were no significant differences in the incidence of hepatic-related treatment-emergent adverse events and hepatic-related serious adverse events for duloxetine compared with placebo in the short-term studies. No patients in the short-term studies, 1-year study, or the sample that was enrolled for 6 months or more met Hy's rule (Hy's rule is defined as an ALT value greater than three times the upper limit of normal together with a total bilirubin greater than two times normal and reflects the presence of hepatocellular injury) [39]. There was a significantly $(p<0.05)$ higher incidence of duloxetine-treated patients $(0.6 \%)$ who discontinued due to a hepatic-related adverse event compared with placebo-treated patients $(0 \%)$. There was no evidence 
that longer-term treatment added to the risk of discontinuation due to a hepatic-related adverse event: $0.6 \%$ of the 350 patients in the 1-year study discontinued due to a hepatic-related adverse event.

\section{Discussion}

This comprehensive safety analysis revealed that the most common TEAEs seen during duloxetine treatment of FM were similar to those seen during duloxetine treatment of other indications, including MDD, GAD, and DPNP. Most TEAEs were mild to moderate in severity and were transient. In the short-term 3- and 6-month studies, adverse events leading to discontinuation varied, with no one event responsible for more than $2 \%$ of patients discontinuing. Overall, 19.5\% discontinued due to an adverse event.

Duloxetine-treated patients had significantly larger increases in BP and heart rates, compared with placebotreated patients, in short-term 3- and 6-month studies. These increases, however, were not of clinical significance. Furthermore, there was no evidence of higher rates of PCS abnormal laboratory values, ECG parameters, vital signs, or changes in body weight, for duloxetine-treated patients compared with placebo-treated patients during 3-6-month treatment, with one exception: A significantly higher incidence of ALT values $>5$ times upper limit of normal was found for duloxetine-treated patients $(0.6 \%)$ compared with placebo-treated patients $(0 \%)$.

Over the course of 1-year open-label of treatment with duloxetine, there was a somewhat higher total incidence of certain adverse events and PCS values on laboratory parameters. In the absence of a comparator, it seems most likely that these increased rates were due to the longer observation period compared with the 3-and 6-month studies. Overall, instances of PCS laboratory values were very low in the sample enrolled for 6 months or longer, as well as in the 1year study, with no discernable clinical pattern suggestive of a specific body system or disease state.

While the overall pattern of adverse events during duloxetine treatment was similar for the FM studies compared with other disorders, the base rate of such adverse events appears somewhat higher in FM. In the treatment of MDD, for example, the incidence of common adverse events has been reported to be generally lower for both placebo and duloxetine than found here [40]. Although initial occurrences of adverse events tend to occur early in treatment, the shorter duration (8-9 weeks) of the MDD trials may account in part for this apparent difference. Discontinuations due to adverse events occurred in about $20 \%$ of patients in both the short-term 3- and 6month studies and the 1-year study. This rate is somewhat higher than the discontinuation rate due to adverse events of $11 \%$ reported in a review of 19 studies of short-term treatment (duration, 8-26 weeks) of MDD with serotonin reuptake inhibitors [41]. Rates of $9-10 \%$ for discontinuation due to adverse events were found across six studies of venlafaxine, a serotonin and norepinephrine reuptake inhibitor of similar class to duloxetine, and four studies of duloxetine, in the short-term treatment of MDD [42]. These findings suggest that patients with FM report slightly more adverse events and have somewhat higher rates of discontinuation due to adverse events compared with other disorders for which duloxetine has been studied, whether on drug or placebo. Nevertheless, clinicians need to be aware of the risk of discontinuation due to adverse events with duloxetine in the treatment of fibromyalgia and balance this risk against the likelihood of treatment response.

The cardiovascular safety of duloxetine has been previously investigated across all conditions for which duloxetine has been studied [43]. Using a database of 42 clinical trials, plus postmarketing safety studies, this recent study found no evidence of cardiovascular risk [43]. Similarly, in the treatment of FM, no evidence of clinically significant changes in ECG parameters or sustained increases in BP was seen for duloxetine relative to placebo. Although duloxetine's noradrenergic effect suggests that it is likely to cause increases in heart rate, only $0.5 \%$ of patients in the 3- and 6-month studies, $0.1 \%$ of patients enrolled for 6 months or more, and $0.6 \%$ of patients in the 1 -year study had a clinically significant increase in pulse rate. The QTc interval was prolonged to a clinically meaningful degree in $0.4 \%$ of duloxetine-treated patients compared with $0.3 \%$ of placebo-treated patients.

In the 3- and 6-month FM studies, small numbers of patients lost or gained $>10 \%$ in body weight. However, among those duloxetine-treated patients who were enrolled for at least 6 months, $7.6 \%$ gained $>10 \%$ in body weight and $4.0 \%$ lost $>10 \%$ in body weight. Similarly, in the 1-year study, $8.0 \%$ gained $>10 \%$ in body weight and $4.9 \%$ lost $>10 \%$ in body weight. In the absence of a placebo or other comparator, these changes over 6 months and 1 year are difficult to interpret. A previous longerterm (1 year) open-label study of duloxetine (80-120 mg/ day) for MDD found early (first few weeks) decreases in mean body weight followed by a return to baseline and then an increase on average of $1.1 \mathrm{~kg}$ by the end of the study [44]. This pattern is consistent with what was found here, with more patients losing $>10 \%$ weight than gaining $>10 \%$ weight in the 3-6 months studies, but more patients gaining $>10 \%$ weight than losing $>10 \%$ weight after being enrolled for 6 months or more and in the 1-year study. The overall mean change, however, was small $(0.7 \mathrm{~kg}$ gain by endpoint of the 1-year study). 
The effect of duloxetine on ALT has been previously found in other populations and is described in the product labeling. Changes in ALT do not appear to predict hepatotoxicity, and the absence of cases that met criteria for Hy's rule during either short- or long-term use supports the conclusion that the risk of hepatotoxicity associated with duloxetine in patients with FM is very low.

There has been considerable attention to the issue of suicide risk with antidepressants $[45,46]$. Because rates of suicidality are typically very low, analysis of a pooled study database is a particularly useful to test for any potential drug-placebo difference. In the analyses of short-term placebo-controlled studies of FM, there were no significant differences between duloxetine and placebo in the incidence of suicidal behavior or ideation according to adverse event reporting. In the 1-year open-label study, four patients were reported to have suicide-related behavior. However, in the absence of a placebo control, these rates of suiciderelated behavior in the longer-term study are difficult to interpret, particularly because elevated rates of suicide have been found for individuals with widespread pain syndromes like FM [47].

Strengths of this study include the large number of patients treated with duloxetine in the shorter-term studies $(n=876)$. In addition, a broad range of safety assessments were conducted. This report on the safety of duloxetine in the treatment of fibromyalgia is limited by the fact that all patients were participants in clinical trials with extensive inclusion/exclusion criteria. In particular, patients with certain comorbidities and patients on most other centrally acting medications were excluded from the trials. In clinical practice, psychiatric and medical comorbidity and polypharmacy is common among patients with FM [48]. Thus, the generalizability of the findings to typical clinical practice patients who have psychiatric or medical comorbidities and who also receive concomitant medications is not known.

Another limitation of this pooled safety analysis includes the lack of a placebo group in the long-term safety study. However, the fact that the safety findings from the longerterm study are generally similar or show only slightly increased rates of adverse events or laboratory/vital sign values, relative to values from the 3- and 6-month studies, may provide reassurance about longer-term use of duloxetine in fibromyalgia.

In conclusion, duloxetine in dosages from 20 to $120 \mathrm{mg} /$ day demonstrated a similar safety and tolerability profile in the treatment of FM to that seen in the treatment of other indications. Most patients tolerate duloxetine without clinically meaningful effects on vital signs, cardiovascular parameters, or laboratory (chemistry, hematology) analytes.
Acknowledgments The authors thank the many clinical investigators who participated in the five studies included in this article. The authors also wish to thank Wei J. Chen, MS, Steve Gelwicks, MS, Indu Lakhani, MS, and Christine M. Young (i3Statprobe) for their assistance with the statistical analyses presented herein. The studies presented here were funded by Eli Lilly and Company and Boehringer Ingelheim $\mathrm{GmbH}$.

Disclosures Dr. Choy has served on advisory boards and speakers bureau for Eli Lilly and Boehringer Ingelheim. Dr. Mease has received grants/research support from Eli Lilly and Company, Pfizer, Inc, Cypress Bioscience, Forest, Allergan, Fralex, and Boehringer Ingelheim; he has been a consultant for Eli Lilly and Company, Pfizer, Inc, Cypress Bioscience, Forest, Allergan, Fralex, Boehringer Ingelheim, Pierre Fabre, and Wyeth; and he is on the Speakers Bureau of Pfizer, Inc. Drs. Kajdasz, Wohlreich, Walker, and Chappell are or were employees of Eli Lilly. Dr. Crits-Christoph has received income from Eli Lilly, Pfizer, Cephalon, Sepracor, and Alkermes.

Open Access This article is distributed under the terms of the Creative Commons Attribution Noncommercial License which permits any noncommercial use, distribution, and reproduction in any medium, provided the original author(s) and source are credited.

\section{References}

1. Wolfe F, Ross K, Anderson J et al (1995) The prevalence and characteristics of fibromyalgia in the general population. Arthritis Rheum 38:19-28

2. McNally JD, Matheson DA, Bakowsky VS (2006) The epidemiology of self-reported fibromyalgia in Canada. Chronic Dis Can 27:9-16

3. Wolfe F, Anderson J, Harkness D et al (1997) A prospective, longitudinal, multicenter study of service utilization and costs in fibromyalgia. Arthritis Rheum 40:1560-1570

4. White KP, Speechley M, Harth M et al (1999) Comparing selfreported function and work disability in 100 community cases of fibromyalgia syndrome versus controls in London, Ontario: the London Fibromyalgia Epidemiology Study. Arthritis Rheum 42:76-83

5. Al-Allaf AW (2007) Work disability and health system utilization in patients with fibromyalgia syndrome. J Clin Rheumatol 13:199-201

6. Robinson RL, Birnbaum HG, Morley MA et al (2003) Economic cost and epidemiological characteristics of patients with fibromyalgia claims. J Rheumatol 30:1318-1325

7. The Multicenter Criteria Committee [MCC] (1990) The American College of Rheumatology 1990 criteria for the classification of fibromyalgia. Arthritis Rheum 33:160-172

8. Nielsen LA, Henriksson KG (2007) Pathophysiological mechanisms in chronic musculoskeletal pain (fibromyalgia): the role of central and peripheral sensitization and pain disinhibition. Best Pract Res Clin Rheumatol 21:465-480

9. Bendtsen L, Norregaard J, Jensen R et al (1997) Evidence of qualitatively altered nociception in patients with fibromyalgia. Arthritis Rheum 40:98-102

10. Bennett RM (1999) Emerging concepts in the neurobiology of chronic pain: evidence of abnormal sensory processing in fibromyalgia. Mayo Clin Proc 74:385-398

11. Gracely RH, Petzke F, Wolf JM et al (2002) Functional magnetic resonance imaging evidence of augmented pain processing in fibromyalgia. Arthritis Rheum 46:1333-1343 
12. Basbaum AI, Fields HL (1984) Endogenous pain control systems: brainstem spinal pathways and endorphin circuitry. Annu Rev Neurosci 7:309-338

13. Clark FM, Proudfit HK (1993) The projections of noradrenergic neurons in the A5 catecholamine cell group to the spinal cord in the rat: anatomical evidence that A5 neurons modulate nociception. Brain Res 616:200-213

14. Legangneux E, Mora JJ, Spreux-Varoquaux O et al (2001) Cerebrospinal fluid biogenic amine metabolites, plasma-rich platelet serotonin and $[3 \mathrm{H}]$ imipramine reuptake in the primary fibromyalgia syndrome. Rheumatology 40:290-296

15. Russell IJ, Michalek JE, Vipraio GA et al (1992) Platelet 3Himipramine uptake receptor density and serum serotonin levels in patients with fibromyalgia/fibrositis syndrome. J Rheumatol 19:104-109

16. Russell IJ, Vaeroy H, Javors M et al (1992) Cerebrospinal fluid biogenic amine metabolites in fibromyalgia/fibrositis syndrome and rheumatoid arthritis. Arthritis Rheum 35:550-556

17. Yunus MB, Dailey JW, Aldag JC et al (1992) Plasma tryptophan and other amino acids in primary fibromyalgia: a controlled study. J Rheumatol 19:90-94

18. Arnold LM, Lu Y, Crofford LJ et al (2004) A double-blind, multicenter trial comparing duloxetine with placebo in the treatment of fibromyalgia patients with or without major depressive disorder. Arthritis Rheum 50:2974-2984

19. Arnold LM, Rosen A, Pritchett YL et al (2005) A randomized, double-blind, placebo-controlled trial of duloxetine in the treatment of women with fibromyalgia with or without major depressive disorder. Pain 119:5-15

20. Russell IJ, Mease PJ, Smith TR et al (2008) Efficacy and safety of duloxetine for treatment of fibromyalgia in patients with or without major depressive disorder: results from a 6-month, randomized, double-blind, placebo-controlled, fixed-dose trial. Pain 136:432-444

21. Chappell AS, Bradley LA, Wiltse C et al (2008) A six-month double-blind, placebo-controlled, randomized clinical trial of duloxetine for the treatment of fibromyalgia. International Journal of General Medicine 1:91-102

22. Chappell AS, Littlejohn G, Kajdasz DK et al (2009) A 1-year safety and efficacy study of duloxetine in patients with fibromyalgia. Clin J Pain 25:365-375

23. Goldstein DJ, Lu Y, Detke MJ et al (2004) Duloxetine in the treatment of depression. A double-blind placebo-controlled comparison with paroxetine. J Clin Psychopharmacol 24:389-399

24. Wernicke JF, Pritchett YL, D'Souza DN et al (2006) A randomized controlled trial of duloxetine in diabetic peripheral neuropathic pain. Neurology 67:1411-1420

25. Raskin J, Pritchett YL, Wang F et al (2005) A double-blind, randomized multicenter trial comparing duloxetine with placebo in the management of diabetic peripheral neuropathic pain. Pain Med 6:346-356

26. Koponen H, Alluglander C, Erickson J et al (2007) Efficacy of duloxetine for the treatment of generalized anxiety disorder: implications for primary care physicians. Prim Care Companion J Clin Psychiat 9:100-107

27. Rynn M, Russell J, Erickson J et al (2008) Efficacy and safety of duloxetine in the treatment of generalized anxiety disorder: a flexible-dose, progressive-titration, placebo-controlled trial. Depress Anxiety 25:182-189

28. Detke MJ, Lu Y, Goldstein DJ et al (2002) Duloxetine $60 \mathrm{mg}$ once daily dosing versus placebo in the acute treatment of major depression. J Psychiatr Res 36:383-390

29. Detke MJ, Lu Y, Goldstein DJ et al (2002) Duloxetine, $60 \mathrm{mg}$ once daily, for major depressive disorder: a randomized double-blind placebo-controlled trial. J Clin Psychiatry 63: 308-315

30. Detke MJ, Wiltse CG, Mallinckrodt CH et al (2004) Duloxetine in the acute and long-term treatment of major depressive disorder: a placebo- and paroxetine-controlled trial. Eur Neuropsychopharmacol 14:457-470

31. Goldstein DJ, Lu Y, Detke MJ et al (2005) Duloxetine vs. placebo in patients with painful diabetic neuropathy. Pain 116: $109-118$

32. Hartford J, Kornstein S, Liebowitz M et al (2007) Duloxetine as an SNRI treatment for generalized anxiety disorder: results from a placebo and active-controlled trial. Int Clin Psychopharmacol $22: 167-174$

33. Gahimer J, Wernicke J, Yalcin I et al (2007) A retrospective pooled analysis of duloxetine safety in 23, 983 subjects. Curr Med Res Opin 23:175-184

34. Stewart DE, Wohlreich MM, Mallinckrodt CH et al (2006) Duloxetine in the treatment of major depressive disorder: comparisons of safety and tolerability in male and female patients. J Affect Disord 94:183-189

35. Lewis-Fernandez R, Blanco C, Mallinckrodt CH et al (2006) Duloxetine in the treatment of major depressive disorder: comparisons of safety and efficacy in U.S. Hispanic and majority Caucasian patients. J Clin Psychiatry 67:1379-1390

36. Mallinckrodt CH, Prakash A, Andorn AC et al (2006) Duloxetine for the treatment of major depressive disorder: a closer look at efficacy and safety data across the approved dose range. J Psychiatr Res 40:337-348

37. Burckhardt CS, Clark SR, Bennett RM (1991) The fibromyalgia impact questionnaire: development and validation. J Rheumatol 18:728-733

38. Cleeland CS, Ryan KM (1994) Pain assessment: global use of the Brief Pain Inventory. Ann Acad Med Singapore 23:129-138

39. Senior JR (2003) Regulatory perspectives. In: Kaplowitz N, DeLeve LD (Eds) Drug-induced liver disease. New York: Marcel Dekker, pp. 739-754

40. Hudson JI, Wohlreich MM, Kajdasz DK et al (2005) Safety and tolerability of duloxetine in the treatment of major depressive disorder: analysis of pooled data from eight placebo-controlled clinical trials. Hum Psychopharmacol Clin Exp 20:327-341

41. Edwards JG, Anderson I (1999) Systematic review and guide to selection of selective serotonin reuptake inhibitors. Drugs 57:507-533

42. Vis PM, van Baardewijk M, Einarson TR (2005) Duloxetine and venlafaxine-XR in the treatment of major depressive disorder: a meta-analysis of randomized clinical trials. Ann Pharmacother 39:1798-1807

43. Wernicke J, Lledo A, Raskin J et al (2007) An evaluation of the cardiovascular safety profile of duloxetine: findings from 42 placebo-controlled studies. Drug Saf 30:437-455

44. Raskin J, Goldstein DJ, Mallinckrodt CH et al (2003) Duloxetine in the long-term treatment of major depressive disorder. J Clin Psychiatry 64:1237-1244

45. Grunebaum MF, Ellis SP, Li S et al (2004) Antidepressants and suicide risk in the United States, 1985-1999. J Clin Psychiatry 65:1456-1462

46. Jick H, Kaye JA, Jick SS (2004) Antidepressants and the risk of suicidal behaviors. JAMA 292:338-343

47. Macfarlane GJ, McBeth J, Silman AJ (2001) Widespread body pain and mortality: prospective population based study. BMJ 323:662-665

48. Weir PT, Harlan GA, Nkoy FL et al (2006) The incidence of fibromyalgia and its associated comorbidities: a population-based retrospective cohort study based on International Classification of Diseases, 9th Revision codes. J Clin Rheumatol 12:124-128 